means of the knife. Superficial absorbent glands, situated about the base of the lower jaw and along the sides of the neck, when enlarged and indurated, can be thus well removed. In such cases, I have frequently resorted to the use of the scalpel with good results, and have assisted my colleagues, Mr. Gay and Mr. Lawson, at the Great Northern Hospital, in similar examples. There is a gland situated close to the under surface of the base of the lower jaw, in near proximity to the facial artery, which often becomes indurated, and needs removal. In performing the operation, care is required that the artery be not cut. I have seen it divided twice lately, in effecting removal of the gland, a complicated wound being produced. Caution must also be observed, when glands of this indurated character are removed, that no great nervous tracts lie in danger of the knife, and that the tumours be not too numerous or deeply seated. In the museum of St. Bartholomew's Hospital is a preparation showing a very extensive mass of indurated cervical glands of fifteen months growth, which was removed by $\mathrm{Mr}$. Vincent from a child six years of age. The case was one badly selected for an operation; for in the mass of glandular tumours are to be recognised branches of the cervical and spinal accessory nerves. The child died shortly after the operation, of debility, with disease of the lungs. The operation, when adopted under advantageous circumstances, is generally easy of execution, and the result all that could be wished for. The scar that remains is usually slight, especially if union of the lips of the wound have taken place by adhesion; and, from all I have seen regarding this mode of permanent riddance of isolated indurated glands, I feel fully justified in adrocating its adoption when feasible.

\section{THE ALCOHOLIC TREATMENT IN EXHAUSTING DISEASES.}

By Jorrs Pursseli, M.D., F.R.C.S., Brighton.

Froy time to time, I have observed various articles in the Journar referring to the administration of what are usually termed stimulants (but which I should submit might with greater propriety be classed as "cordials") in the successful treatment of acute aud chronic disease, and which the late eminent Dr. Todd sanctioned by his long continued observation and experience as the only means calculated to restore the exhausted nervous energy of a suffering patient. I am therefore induced to give in brief detail a few of the many cases I have restored by the free administration of brandy, wher each and every one of the patients' cases appeared hopeless under any other treatment.

CASE I. I shall commence with the last case under treatment, that of a young female of 16 , nursemaid in a family, a patient of the eastern district of the Brighton Dispensary, to which I am the medical ofticer. At the present time she is progressing towards convalescence from bed-sores. This patient was the subject of acute rheumatism three months since, with the frequent concomitant of acute pericarditis. She was treated on the alkaline plan with morphine and opium, and counterirritation on the spine, and in about ten days was convalescent. Chorea of the right upper and lower extremity gradually supervened, which continued to increase; and the jactitation of the upper extremity was so severe, that the limb was obliged to be held down and confined by attendants; while at the same time the patient, who had all along been ordered weak brandy and water, continued to experience great exhaustion and physical depression, which increased to such an extent that it was apparent death from exhaustion must speedily occur unless the nervous system could be rallied. At half-past 11 A.M. I administered with my own hand, by means of a tablespoon, about a pint of brandy diluted with one-third of cold water. At halfpast 4 I revisited the patient, and found her slightly improved, and gave her rather more than a pint similarly diluted. From this time a marked change for the better took place, and she gradually recovered; her convalescence being only retarded by bed-sores. Hut for the exhibition of this cordial, certain death was imminent, and that in a few hours.

CASE II. I had for many years attended an elderly lady, who was frequently the subject of gastric disturbarice arising from indulgence at the table in indigestible articles of diet, inducing diarrhce, etc., and occasionally immediate or remote cerebral congestion. 'Twice or thrice she had been in articulo mortis, and once she appeared to have expired, when brandy diluted as above was exhibited, in the quantity of a pint or a pint and a half, with the result of restoring sensibility in a few hours.
This lady continued to live several subsequent years, in the enjoyment of excellent health. The usual treatment by counterirritation and laxatives had been previously pursued.

CASE III. I was called up at 4 one morning, about six years ago, to visit a youth of 13 , who had been under treatment for arachnitis, and became convalescent. Feeling greatly exhausted a few days subsequently, from having been imprudently driven too long a distance into the country, he experienced a re. lapse, when my attendance was urgently requested. I adopted the usual remedies, with counterirritation on the spine, etc. On being summoned early in the morning, I found my patien fast sinking, evidently from exhaustion, and not from inflam mation or its consequences. I called for some brandy, which having been mixed with one-third of water, I succeeded in getting down quickly; but, while thus engaged, our young patient appeared to be expiring. The attendants, being all paralysed at the emergency of the case, left me to make the best of it. I continued the administration of the brandy until I had fairly given upwards of a pint, when the patient began to make long and deep inspirations. He quite recovered, and is now a fine grown youth in excellent health. The late Dr. Bor land, of Newington Place, saw this case at $\tau$ A.M., when the sensibility of the patient was restored, and expressed his grea surprise and approbation of the success of this remedial agent.

CASE Iv. I was called to attend a respectable middle-aged married female, about five years since, the subject of an attack of profuse menorrhagia. As I was from home in the country, my assistant attended and took charge of the patient. On my return and visiting this patient, I found ber still flooding, and in a sinking condition. Having bandaged her, and applied cold to the uterine region, I immediately gave brandy diluted to the extent of a pint, and ordered opium in one grain doses with quinine every six hours. In about five days this patient was con valescent, having taken the contents of two bottles of brandy, besides the opium and quinine. She is at this time, and has been ever since, in the enjoyment of excellent health. I should have stated that this patient was scarcely or but partially sensible when I saw her on my first visit, so completely drained had been the circulatory system-a proof that alcohol, in all these cases, possesses the essential properties of a nutritive aliment of the nervous system.

Such had long been my opinion before Dr. Todd's views ap peared in print. I can safely add that $I$ have been more successful in the treatment and cure of acute and chronic disease by the timely and judicious exhibition of what are termed " stimulants"-by which I mean cordials, as brandy more or less diluted, and wine and beer-than by any other class of dietetics. Many have been the cases of supposed "heart-disease", indicated by frequent palpitations, sensations of fluttering, inordinate action, etc., which have yielded to a moderate allowance of beer, wine, etc., twice or thrice daily, in conjunc tion with a generous diet of meat, bread, and avoiding indigestible articles, such as cheese, pastry, etc.

In conclusion, to withdraw from a patient suffering from acute or chronic disease his accustomed aliment, and to keep him on what is termed " a low diet", must aggravate his malady, and is diametrically opposed to common sense, ard will indefinitely protract his disease and counteract the direct exercise of the vis medicatrix natura in restoring the healthy and reparative processes of nature.

For the last twenty years I have been in the habit, from long and continuous observation in public and private practice, of recommending the moderate use of wine or beer in the treatment of most acute, subacute, and chronic diseases with the greatest success; and I am convinced it is the only plan calculated to counteract the varied and manifold effects of disorder and disease, and to restore the inestimable blessing of health. There is of course " no rule without an exception." The state of the pulse, skin, and tongue, the marked presence or absence of physical prostration, constitute the chief indications to determine the employment of the above auxiliaries in the treatment of disease.

I should here remark, that I have never observed any apparent inebriating effects to follow the administration of large doses of diluted alcohol; with a fuller and more regulated pulse, calm and refreshing sleep usually succeeds, terminating in the rapid recovery of the patient. Almost all the cases in which $I$ have succeeded in restoring the vital energy of a patient where immediate death appeared to be the inevitable result, were those of individuals, with two or three exceptions, who usually drank water as a beverage.

I propose in a future Journal to submit some further re- 
marks on the treatment of chronic disease by the auxiliary employment of cordials, together with medical and dietetic treatment; and shall endeavour to show that by their agency, illustrated by the detail of some cases both in public and private practice, disorder and disease are more speedily arrested, and convalescence established, than could have been accom. plished without the exhibition of these restoratives.

\section{Cransactions of 邀ramethes.}

\author{
CAMBRIDGE AND HUNTINGDON BRANCH.
}

PNEOMOTHORAX WITHOOT URGENT SYMPTOMS, FOLLOWED BY RECOVERY : SUBSEQUENT DEATH OF THE PATIENT FROM DISSECTING ANEURISM OF THE AORTA.

By W. H. Rankina, M.D.Cantab., Fellow of the Royal College of Physicians of London.

[Read at Cambridge, July 10th, 1860.]

THE following case is more than usually interesting on two grounds ; first, as exhibiting an instance of recovery from idiopathic pneumothorax, and secondly as offering an additional instance of a still more rare disease-dissecting aneurism of the aorta.

A young man of delicate aspect, aged 19, was, while at church, suddenly seized with acute pain in the left side, accompanied by intense suffocative dyspncea. He was removed home, and soon placed in bed, when his breathing gradually became more tranquil. I saw him the next day, in the following condition:-He was sitting up in bed, much disliking the confinement, which he chose to think was unnecessary. The breathing was short; but free from pain or anxiety of countenance. From the history of his seizure, contrasted with his comparatively comfortable condition at the moment, I was at first at some loss what to expect; but from habit, rather than from any suspicion of serious disease, I examined the chest. In doing so, I was not a little surprised at the physical signs which presented themselves.

On inspection, the whole of the left side was rounded, and mo. tionless, with the intercostal spaces obliterated, as in empyema. The percussion note, however, was tympanitic universally, and to the most marked degree; there was also entire absence of natural breath sound; all was silent, with the exception of amphoric blowing under the angle of the scapula, and well defined metallic tinkling. The heart was beating also considerably to the right of the sternum. These physical signs were clearly referable to the presence of air and fluid in the left pleura, generally supposed, in almost all cases, with the exception of those arising from external violence, to depend upon perforation of the lung connected with a tubercular cavity. But nothing in this patient's history betrayed any condition from which this species of perforation could have proceeded. There was no trace of phthisis, - no evidence of violent bodily exertion; he was, in faot, sitting quietly in church when the pneumothorax occurred.

Speculation as to the origin of this rare condition was so obviously useless, that our therapeutic efforts were directed alone to the meeting of any urgent symptom which might arise, and which general experience taught us would arise. To our gratification, however, as well as surprise, the patient steadily improved; the lung expanded, and in, I believe, two months he was again engaged in his usual avocations. From this time, until about three months since, which was the date of the next rare episode in the patient's pathological life, I did not hear or see anything of him.

On this latter occasion, I was, in common with several other medical practitioners, summoned hastily, and found the patient dead on my arrival. It seemed, from the history given me in explanation of this sudden event, that on the 12th of May he complained, while at his office, of faintness, with pain in the back. He took some stimulant, and speedily recovered sufficiently to walk home. Next day, he took some domestic remedy, under the impression that he was suffering from dyspepsia; but he did not seek any medical advice. On the next day, he went again to the office, and there again complained of pain in the back and loins. The same evening he was remarkably full of spirits, and sat up late. He went to the office, as usual, next morning, returned to dinner, and again returned to the office, complaining of some pain in walking. He had not been long in the office, before he uttered a loud cry, and became faint and collapsed; he was laid down, and soon recovered sufficiently to be taken home. On his arrival, he felt so much better as to request to be allowed to walk up stairs. This, horrever, was not acceded to, and he was carried up; but he undressed himself and got into bed without assistance. A friend sat for some time, but finding him apparently better, he left him, and went down stairs. He had scarcely done so, when he heard a loud shriek, and, rushing up, found the patient in the agonies of death.

A post mortem examination was made twenty-four hours after death. The corpse was that of a tall thin young man. The thorax had been opened before my arrival, and from the right pleura two quarts of fluid blood had been taken. As I was anxious not only to discover the immediate cause of death, but also the condition of the left lung after his prior attack, the thoracic organs were carefully scrutinised. There were no pleural adhesions on either side, nor was there any appearance attributable to the previous attack of pneumothorax. Both lungs, though small from compression, were entirely free from tubercle, there were a few dilated air-cells, especially near the apex of the left lung, where several cells had been ruptured into one. Below the left lung a large fluctuating bag was seen, extending the whole length of the thorax. This proved to be fluid behind the costal pleura, and an incision determined it to be semi-coagulated blood. The heart and lungs were now removed, by dividing the trachea and œsophagus in the neck, and detaching them from above downwards, when the entire track of the aorta through the diaphragm was seen to be infiltrated with clotted blood, particularly in the posterior mediastinum, where it existed in large quantity. The same condition also extended throughout the track of the abdominal aorta, as far as the iliac arteries, and blood had been extravasated extensively between the folds of the mesentery, and into the pelvic cellular tissues. The pericardium was free, and did not contain any fluid. The heart was of medium size, and of healthy consistence. The outer coat of the aorta was marked in front by patches of extravasated blood, of the nature of ecchymosis; but, in its posterior aspect, from its origin it was surrounded with clotted blood to such an amount as to make dissection difficult. The heart, when opened, presented perfectly healthy valves; but the ascending aorta, from about a quarter of an inch above the valves, exhibited the appearances known as those of dissecting aneurism. The inner and middle coats were seen to be separated by a layer of coagulated blood, to the extent of half an inch at the base, and throughout the whole track of the vessel, even to its abdominal portion. The lining membrane of the vessel was healthy, with the exception of a few small specks of atheroma; and in one spot, in the upper aspect of the arch, was a small slit, not more than threeeighths of an inch long, through which the extravasation appeared to have taken place. The point of exit of the blood into the cellular tissues, in the mediastinum, and into the right pleura, could not be found, as the examination was performed under very unfavourable circumstances. It may be stated that the liver and other abdominal organs were sound.

REMARRS. In reviewing the pathological history of this remark able case, the first obscure point is the nature of the lesion which gave rise to the pneumothorax. This condition is, as it is well known, an occasional concomitant of phthisis, in which case there is no difficulty in explaining its occurrence, by the perforation of the pleura investing a phthisical cavity; this is, in fact, the mode of its production in the great majority of cases. But, in the present case, there had not been any antecedent history of tubercle, neither was there any post mortem evidence of it. Could the air have gained access to the pleural cavity by rupture of the congregated emphysematous air-cells previously adverted to? I believe this to be a rational explanation, and that its probability is favoured by the comparatively little intensity of the symptoms, and by the absence of any indications of that vascular disturbance which the presence of purulent fluid in the pleural cavity would have produced. In reference to the occurrence of dissecting aneurism of the aorta, this case may be said to be invested with still further interest, from the actual rarity of the accident. At the time I placed one instance on record (in 1847) only twenty.one cases had been published, and since, as far as I am able to ascertain, but six or eight have been met with; so that thirty-two or three will be the outside number from which our acquaintance with this peculiar lesion is derived. In the present instance, the moment of the original rupture of the inner coat of the vessel seems to have preceded death by several days, and may clearly 